\title{
SÜTÜN MİKROBİYOTASI VE BOZULMASINA YOL AÇAN ÖNEMLİ BAKTERİLER
}

\author{
Cem Sezai Başar ${ }^{*}$ Zeynep Dilek Heperkan ${ }^{2}$ \\ 1 İstanbul Aydın Üniversitesi, Lisansüstü Eğitim Enstitüsü, Gıda Güvenliği ve Beslenme Programı, İstanbul, \\ Türkiye \\ 2 İstanbul Aydın Üniversitesi, Gıda Mühendisliği Bölümü, İstanbul, Türkiye
}

Geliş / Received: 31.01.2021; Kabul / Accepted: 18.03.2021; Online bask1 / Published online: 23.04.2021

Başar, C.S., Heperkan. Z.D. (2021). Sütün mikrobiyotası ve bozulmasına yol açan önemli bakteriler. GID $A$ (2021) 46 (3) 660-668 doi: 10.15237/gida.GD21034

Basar, C.S., Heperkan. Z.D. (2021). Milk microbiota and its important spoilage bacteria. GIDA (2021) 46 (3) 660 668 doi: $10.15237 /$ gida.GD21034

\section{ÖZ}

Süt sağımdan başlayarak işleninceye kadar çeşitli ortamlardan, ekipmanlardan ve personelden bulaşan mikroorganizmalar nedeniyle bozulur. Süt mikrobiyotasında laktik asit bakterileri, psikrotrofik Gram negatif bakteriler, Gram pozitif sporlu bakteriler ve patojen bakteriler bulunur. Bu bakteri ve enzimlerin faaliyeti sütün duyusal ve yapısal özelliklerini değiştirerek bozulmasına neden olur. Çiğ süt mikrobiyotası hem sütün hem de süt ürünlerinin kalite ve güvenliğini etkileyen en önemli parametrelerden birisi olup, bir taraftan çiftlik ortamını yansıtırken, diğer taraftan sağım ve işletme koşullanı hakkında da fikir verir. Çı̆ğ sütte sıklıkla bulunan ve sütün bozulmasına yol açan en önemli bakteriler Pseudomonas, Acinetobacter, Brevundimonas, Flavobacterium ve bazı koliform üyeleridir. Sütün bozulmasında pastörizasyon öncesi bulaşmaların yanında pastörizasyon sonrası bulaşmalara bağlı mikroorganizma faaliyeti de önemli rol oynar. Özellikle psikrotrofik termofilik karakterdeki Bacillus türleri pastörizasyondan sonra meydana gelen bozulmalardan sorumludur. Bu makalede, sütün mikroorganizmalarla bulaşma yollanı, sütte bulunan mikroorganizmaların özellikleri ve sütün bozulmasındaki rolleri konusunda bilgiler sunulmuştur.

Anahtar kelimeler: Mikrobiyel bozulma, süt, Pseudomonas, Bacillus, Paenibacillus

\section{MILK MICROBIOTA AND ITS IMPORTANT SPOILAGE BACTERIA}

\begin{abstract}
Milk spoils due to microorganisms transmitted from environments, equipment and personnel starting from milking to process. Lactic acid bacteria, psychrotrophic Gram negative bacteria, Gram positive spore-forming bacteria and pathogenic bacteria are present in the milk microbiota. The activity of these bacteria and enzymes changes the sensory and structural properties of milk, causing it to spoil. Milk microbiota is one of the most important parameters affecting the quality and safety of both milk and dairy products. Bacteria found in milk that cause milk spoilage are Psendomonas, Acinetobacter, Brevundimonas, Flavobacterium and some coliform members. Besides contamination before and after pasteurization, microorganism activity also plays an important role in spoiling milk. Especially, Bacillus species with psychrotrophic thermophilic character are responsible for the deterioration that occurs after pasteurization. In this article, information on the ways of contamination of milk with
\end{abstract}

* Yazışmalardan sorumlu yazar / Corresponding author

$\bowtie$ : csezaibasar@stu.aydin.edu.tr

(c): +905324685987

Cem Sezai Başar; ORCID no: 0000-0001-8915-9576

Zeynep Dilek Heperkan; ORCID no: 0000-0001-7801-9607 
microorganisms, the characteristics of microorganisms as well as their roles in milk spoilage are presented.

Keywords: Microbial spoilage, milk, Psendomonas, Bacillus, Paenibacillus

\section{GİRİŞ}

Süt, zengin besin içeriği ve uygun yapısal özellikleri nedeniyle pek çok mikroorganizmanın gelişmesine uygun bir gida maddesidir. Mikroorganizma yükü ne kadar yüksek ise süt o kadar kısa sürede bozulur. Mikroorganizma sayıs1 ile birlikte sütün bozulmasını etkileyen bir diğer önemli faktör sicaklıktır. Sicaklık ile bozulma doğru orantılı olup, sicaklık arttıkça sütün bozulması hızlanır, başka bir ifadeyle sıcaklık yükseldikçe süt daha çabuk bozulur. Süt, sağım sirasinda meme kanali, personel, sağımda kullanılan kaplar veya sağım makinesi, tank ve depolardan kaynaklanan, çok sayıda ve çeşitli mikroorganizmalarla bulaşabilir (Nieminen vd., 2007). Çiğ süt mikrobiyotası bir taraftan çiftlik ortamını yansitırken, diğer taraftan sağım ve işletme koşulları hakkında da fikir verir. Süt hayvanları, barınaklar ve meraların temiz ve bakımlı olması, sağımın hijyenik koşullarda yapılması, sütün soğutulması ve soğuk zincirin korunması, işletmenin sanitasyon kurallarına uygun şekilde tasarım ve üretimi, sütte mikroorganizma sayısının önemli derecede düşük olmasını ve dolayısıyla süt kalitesinin yüksek olmasını sağlar (Dousset vd., 2016; Martin vd., 2019). Genel görüş olarak, meme içindeyken sütün mikroorganizma içermediği, sütte bulunan mikroorganizmaların sağımla birlikte meme derisi, dış ortam veya yavruların ağız boşluğundan kaynaklandığı düşünülüyordu. Son yıllarda yapılan çalışmalar ise meme bezi içinde endojen bir mikrobiyotanın varllğını göstermektedir (Addis vd., 2016; Fusco vd., 2020). İneklerde bağırsak bakterilerinin meme bezine geçişi metagenomik araşturmalar ile kanıtlanmıştır (Young vd., 2015). Sağlıklı, emziren ineklerde dışkı, süt lökositleri ve kan lökositleri mikrobiyotasinda yer alan Ruminococcus, Bifidobacterium cinsleri ve Peptostreptococcaceae ailesine ait türlerin ortak varllğ1 aynı hayvanlardan alınan örneklerle gösterilmiştir (Young vd., 2015). Bakterilerin, bağırsak lümenini terk ederek mezenterik lenf dügümlerinden meme bezine, muhtemelen dendritik hücreler gibi immün hücreler yoluyla geçebileceği böylece, memeden farklı anatomik bölgelerden bir şekilde meme bezine girebileceği belirtilmiştir (Addis vd., 2016; Fusco vd., 2020). Sütün sağımı ve bunu izleyen taşıma, depolama, süt ürünlerine dönüştürme, pastörizasyon ve pastörizasyon sonras1 aşamalar dahil geçirdiği tüm evrelerde meydana gelen değişiklikleri anlayabilmek ve değerlendirebilmek için çiğ sütün mikrobiyolojik kalitesinin bilinmesi çok önemlidir (Boor vd., 2017; Dortey vd., 2020). Bu makalede, sütün mikroorganizmalarla bulaşma yolları, sütte bulunan mikroorganizmaların özellikleri ve sütün bozulmasındaki rolleri konusunda son yıllarda yapılan çalışmalara ait bilgilerin sunulması amaçlanmıştır.

\section{SÜTÜN BOZULMASI VE İLGİLİ MİKROORGANIZMALAR}

Mikroorganizma faaliyetleri sonucunda meydana gelen bozulmalar ile süt ve fermente sütün yaklaş1k \%30'unun kayıp olduğu bildirilmiştir (Trmcic vd., 2015). Sütün bozulmasinda pastörizasyon öncesi bulaşmaların yanında pastörizasyon sonrası bulaşmalara bağlı mikroorganizma faaliyeti de önemli rol oynar (Ryser vd., 2016). Pastörizasyon sonras1 bulaşmaların süt endüstrisinde ciddi bir sorun olduğu, bu tip bulaşmanın daha çok perakende düzeyinde meydana geldiği ve tüketici hatalarının da önemli payı olduğu bildirilmiştir (Golan ve Buzby, 2015; Martin vd., 2018). Sütün mikroorganizmalar ile bulaşmasında meme bezi içindeki endojen mikrobiyotanın yanında dış ortamdan örneğin sağım personel ve ekipmanları; süt taşıma ve depolama ekipmanları, hava, su, toprak, ot/yem gibi kaynaklar ve sütle beslenen yavruların ağız boşluğu rol oynar. Sütte bulunan mikroorganizmalar farklı araşturcılar tarafindan değişik kriterler dikkate alınarak sınıflandırılmaktadır. Örneğin bazı kaynaklarda süt mikrobiyotası, bakterilerin Gram boyamaya karşı gösterdikleri reaksiyonlara göre Gram pozitif ve Gram negatif olmak üzere 2 gruba ayrilarak incelenir (Trmcic vd., 2015; Lu vd., 2017). Diğer baz1 kaynaklarda bozulma yapan, sporlu ve patojenik gibi bakterilerin fonksiyonel, morfolojik ve fayda-zarar özellikleri birlikte dikkate alınarak 
sınıflandırma yapılmaktadır (Rodrigues vd., 2017). Literatürde karşılaşılan bir diğer sınıflandırma ise; pastörizasyon sonrası bulaşanlar ve psikrotolerant gram negatif bakteriler olmak üzere 2 grup halinde yapilır (Martin vd., 2012). Ancak, mikroorganizmaları tespit etmek için kullanılan yöntemler ve özellikle omik teknolojilerdeki gelişmeler çiğ sütün daha önce düşünülenden daha heterojen ve karmaşık bir mikrobiyotaya sahip olduğunu göstermiştir (Fusco vd., 2020). Bu makalede sütün özellikleri de göz önüne alınarak sütte bulunan bakteriler dört grup altunda toplanmıştır; (i) laktik asit bakterileri (LAB), (ii) psikrotrofik Gram negatif bakteriler, (iii) Gram pozitif sporlu bakteriler ve (iv) patojenik bakteriler (Şekil 1).

\section{LAKTİK ASİT BAKTERİLERİ}

Çiğ sütte Lactococcus, Streptococcus, Lactobacillus, Enterococcus ve Leuconostoc gibi laktik asit bakterileri bulunabilir (Rodrigues vd., 2017; Fusco vd., 2020). Sütte bulunan LAB içinde sayı bakımından en yüksek olan Streptococcus türleridir (Rodrigues vd., 2017). Soğuk zincirin kırılması veya sütün oda sicaklığında bekletilmesi LAB'ın laktozu hidrolize ederek laktik asit oluşturmasına neden olur. Asit oluşumu sütte $\mathrm{pH}$ 'nın düşmesine ve tadın ekşimesine yol açtı̆̆ından içme sütünde LAB sayısının yüksek olması istenmeyen bir durumdur.

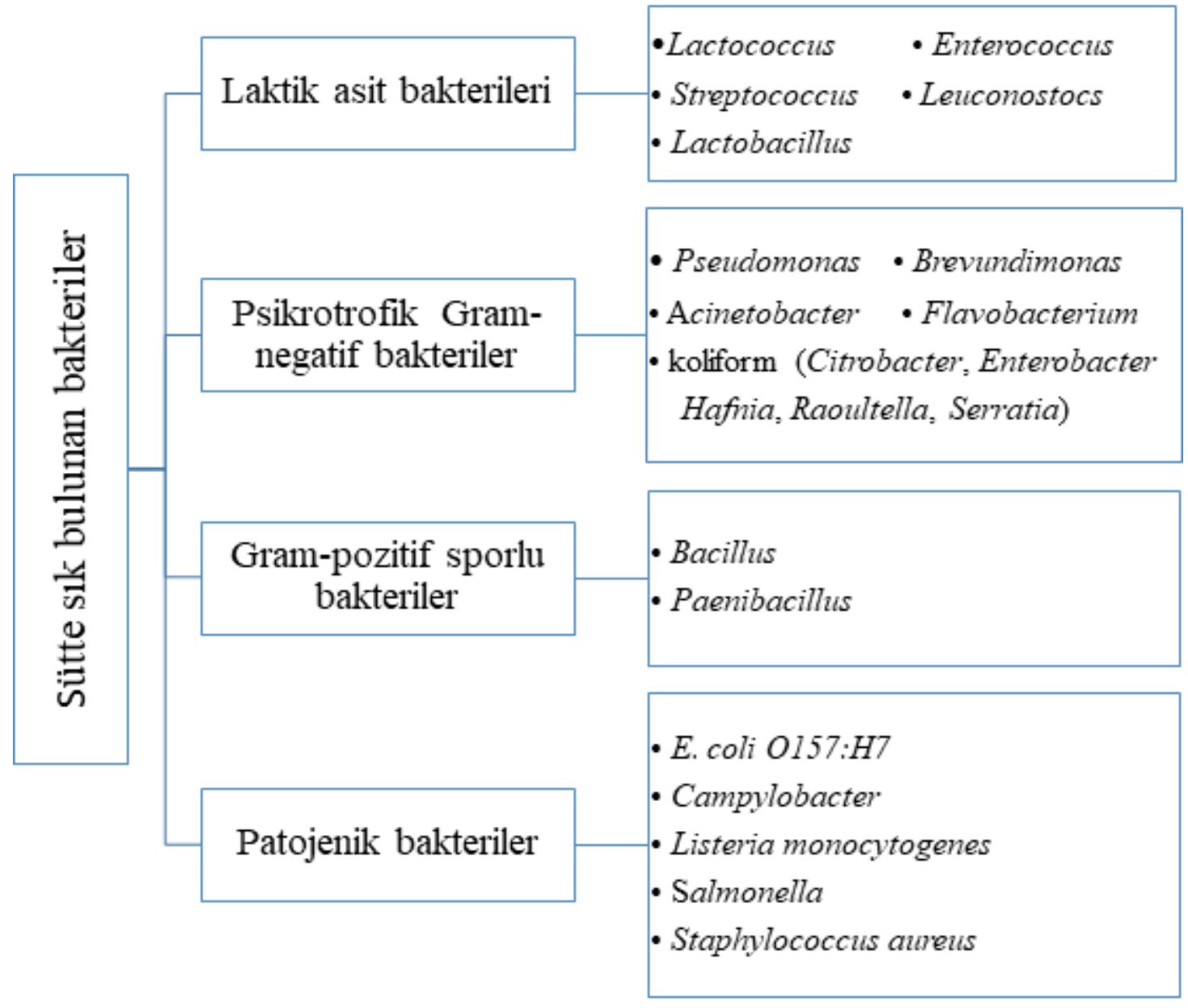

Şekil 1. Sütte s1k bulunan bakteriler 
Sütün soğutulması, pastörize edilmesi ve daha sonra soğukta depolanması LAB sayısında azalmayla sonuçlanır. Sütün aksine, peynir (Wyder vd., 2019) ve yoğurt gibi süt ürünlerinde ise LAB sayısının yüksek ve aktif olması, laktozu fermente etmesi ve bakterinin türüne ve üretilen fermente ürüne bağlı olarak başta asit olmak üzere diasetil, hidrojen peroksit ve bakteriyosin gibi metabolitleri üretmesi istenir. Laktik asit bakterilerinin dışında sütte Propionibacterium, Microbacterium ve Micrococcus gibi diğer sporsuz Gram pozitif bakteriler de bulunur (Trmcic vd., 2015; Holzapfel vd., 2020; Techer vd., 2020).

Çiğ süt gibi, pastörize sütün de bakterilerle bulaşması sık karşılaşılan bir durumdur. Pastörizasyondan sonra olan bulaşmalarda az da olsa laktik asit bakterilerinin de yer aldığ1 ve sütün bozulmasında rol oynadığı belirlenmiştir. Örneğin ticari pastörizasyon veya laboratuvar pastörizasyonu olarak adlandırılan düşük sıcaklıkuzun süre $\left(63^{\circ} \mathrm{C} / 30 \mathrm{dk}\right)$ uygulanmıss sütlerden Lenconostoc lactis, Lactococcus lactis ve Enterococcus sp., düşük sicaklık-kisa süre $\left(72^{\circ} \mathrm{C} / 25 \mathrm{~s}\right)$ uygulanmış sütlerden Micrococcus sp., Streptococcus thermophilus ve $77^{\circ} \mathrm{C} / 25$ s isıl işlem uygulanmış sütlerden Staphylococcus pasteuri izole edilmiştir (Caplan vd., 2013; Trmcic vd., 2015). Bu mikroorganizmalar içinde hücre dışına ekzopolisakarit salgılayan Leuconostoc türlerinin sütte sünme (ropy) kusuruna ve bu nedenle ekonomik kayba neden olduğu bildirilmiştir (Trmcic vd., 2015). Sünme kusuruna neden olan bakterilerin araşturldığı bir çalışmada, laktik asit bakterileri içinde sadece Leuconostoc lactis ve Lactococcus lactis' in $6^{\circ} \mathrm{C}$ 'de gelişme gösterdiği belirlenmiş, bu nedenle soğukta depolanan sütteki bozulmadan da (sünme) bu iki bakterinin sorumlu olabilecekleri bildirilmiştir (Trmcic vd., 2015).

\section{PSİKROTROFİK GRAM NEGATIIF BAKTERILER}

Sütün sağımdan sonra soğutulması ve işleninceye kadar soğukta saklanması psikrotrofik bakterilerin baskın florayı oluşturmasina neden olur. Sütün bozulmasina yol açan psikrotrofik Gram negatif bakteriler içinde en sık bulunan türler; Pseudomonas ve Acinetobacter üyeleridir (Ribeiro vd., 2018; Fusco vd., 2020). Ayrica Brevundimonas, Flavobacterium ve koliform üyeleri de daha az rastlanan ve sütün bozulmasindan sorumlu diğer psikrotrofik bakterilerdir (Trmcic vd., 2015; Koppenaal vd., 2017; Júnior vd., 2018). Bozulmaya neden olan bu bakteriler sütte, koku ve tat kusurlarına yol açabilen lipaz veya proteaz enzimlerini üretirler (Glantz vd., 2020; Fusco vd., 2020). Yapilan araştırmalarda süt ve süt ürünlerinden izole edilen Pseudomonas izolatlarının sirasiyla $\% 33$ ve $\% 52$ 'sinin proteaz aktivitesine sahip olduğu gösterilmiştir (Caldera vd., 2016; Machado vd., 2017). Pseudomonas türleri içinde $P$. fragi, P. gessardii, P. fluorescens, P. rhodesiae, P. brenneri, $P$. proteolytica sütün bozulmasina siklikla yol açan türlerdir (Jonghe vd., 2011; Trimcic vd., 2015; Caldera vd., 2016).

Psikrotrofik bakteriler, özellikle Psendomonas ve Acinetobacter türleri tarafindan üretilen 1siya dayanıklı, proteolitik ve lipolitik enzimler pastörizasyon aşamasından sonra sütün bozulmasina neden olur (von Neubeck vd., 2015; Yuan vd., 2018; Yuan vd., 2019). Lezzet kusurlarının yanında sütteki en önemli bozulma proteolize bağlı olarak oluşan pıhtılaşmadır. Bu tip bozulma UHT sütlerde karşılaşılan önemli bir sorundur (Zhang vd., 2019).

Sütte yüksek lipo-protein lipaz (LPL) miktarının yüksek bakteri sayısı ile ilişkili olduğu bulunmuştur (Barbano vd., 2006). Lipo-protein lipaz, sığır sütündeki başlıca lipazdır ve sütte teknolojik açıdan en önemli enzim olarak kabul edilmektedir (O'Mahony vd., 1990). Lipolitik aktivite, serbest yağ asitleri (FFA) ve diğer yağ asitleri ile ilişkili olup, özellikle kısa zincirli yağ asitlerinin süt tadında bozulmaya neden olduğu belirlenmiştir (Glantz vd., 2020).

Sütte sünme kusurunun nedeni olan psikrotrofik koliform bakterilerin ayrımında minimum gelişme sıcaklığının önemli olduğu bildirilmiştir. Sütte bozulmaya yol açan Hafnia paralvei, Citrobacter, Enterobacter, Serratia, Rabnella inusitata, Raoultella ve Klebsiella gibi koliformlar arasında özellikle Rabnella inusitata' nın $6^{\circ} \mathrm{C}$ 'de iyi gelişme gösterdiği ve sütteki sünme kusurundan sorumlu olduğu belirtilmiştir (Trimcic vd., 2015; Hahne vd., 2018). 


\section{GRAM POZITIIF SPORLU BAKTERİLER}

Sütün pastörizasyon sonrası proteolitik ve lipolitik enzimlerle bozulmasina hem spor oluşturan hem de spor oluşturmayan Gram pozitif bakteriler neden olabilir. Psikrotolerant-termodurik (soğuğa toleransl1-yüksek sıcaklığa dayanıklı) sporlu bakteriler sütün sağımını izleyen soğutma aşamasında çoğalır ve spor formunda daha sonraki 1 sıl işlemde canlı kalarak sütün bozulmasına yol açar (De Jonghe vd., 2010; Doyle vd., 2015; Ribeiro vd., 2020). Bu tür bir bozulmaya, spor oluşturan bakterilerden Paenibacillus cinsi ve Bacillus weihenstephanensis gibi soğuğa toleranslı bazı Bacillus türleri neden olur (Ranieri vd., 2012; Trimcic vd., 2015). Bu organizmalardan kaynaklanan bozulma, sütün $6^{\circ} \mathrm{C}$ civarında depolanması durumunda tipik olarak 17 ila 21 gün raf ömründe meydana gelir (Trimcic vd., 2015; André vd., 2017). Bacillus ve Paenibacillus sütün bozulmasına yol açan en önemli sporlu bakterilerdir (Ranieri vd., 2012; Trimcic vd., 2015; Olajide vd., 2020). Bacillus türleri içinde sütün bozulmasina en sik yol açan türün $B$. cereus olduğu bildirilmiştir (De Jonghe vd., 2010; Porcellato vd., 2020). Ayrica, Bacillus cereus ve $P$. polymyxa kuvvetli proteolitik ve lesitinaz aktivitesi ile hem proteinlerin parçalanmasından hem de sütte yağ zerrelerinin kümelenmesinden kaynaklanan acı krema kusurlarından sorumludur (De Jonghe vd., 2010; Murphy vd., 2016). Bacillus pumilus sadece kuvvetli lipolitik aktivite gösterirken, B. amyloliquefaciens ve B. subtilis'in hem kuvvetli lipolitik hem de proteolitik aktiviteye sahip olmaları nedeniyle sütün bozulmasında önemli rol oynadıkları bildirilmiştir (Coorevits vd., 2008; De Jonghe vd., 2010). Bu türlere ilave olarak B. clausii ve B. licheniformis türlerinin de sütte bozulmaya yol açtuğ belirlenmiştir (De Jonghe vd., 2010; Miller vd., 2016). Yeni türlerin ve soyların sik sik yeniden siniflandirilip tanımlanması nedeniyle Bacillus türlerinin isimlendirilmesinde önemli değişiklikler olduğunu vurgulayan araştırıcılar, Bacillaceae familyasına ait bir izolata tür adı atamanın zor olduğunu belirtmişler ve çözüm olarak farklı genotiplere güvenilir sinıflandırma sağlayan $r p o B$ (RNA polimeraz beta subunit) geninin de kullanılmasinı önermişlerdir (Trimcic vd., 2015).

\section{SONUÇ}

Dünya genelinde çiğ süt üretimi 2018'de 842 milyon ton, Türkiye'deki süt üretimi ise 22 milyon tondur (IDF, 2019; FAO, 2019). Sütün yaklaş1k \%30'luk kısmı bozularak atılmaktadır. Diğer yandan hem çiğ hem de pastörize sütün ve süt ürünlerinin çok sayıda gıda kaynaklı hastalı̆ga yol açtığ1 bilinmektedir (Guh vd., 2010; Weiler vd., 2011; Jones vd., 2019). Süt sağımının hijyenik koşullarda yapılmaması, barınakların temiz ve bakımlı olmaması, ekipmanların temizlik ve dezenfeksiyonuna dikkat edilmemesi, suyun temiz olmamas1, süt hayvanlannda mastitis (meme iltihabı) gibi hastalıkların varlığı ve işletmenin sanitasyon kurallarına uygun üretim yapmamas1 gibi nedenler sütün bozulma yapan ve patojen bakterilerle bulaşmasına neden olur. Süte bulaşan mikroorganizmaların sayım ve tanımlanmasında kültüre bağlı ve kültürden bağımsız olmak üzere çeşitli yöntemler kullanılmaktadır. Çiğ süt mikrobiyotasının mikrobiyolojik analizlerinin çoğu kültüre bağlı yöntemlere dayanmaktadır (Kırdar 2017; Redrigues vd., 2017). Süt endüstrisindeki standart mikrobiyel testler, toplam mezofilik bakteri sayımına ve mikrobiyel bulaşmanın göstergesi olarak enterobakterilerin sayısını belirlemeye odaklanmıştır (Sadiq vd., 2016; Fusco vd., 2020). Mezofilik bakteri sayısının 200 bin $\mathrm{KOB} / \mathrm{mL}$ 'den fazla olması bulaşmanın yüksek, 200 bin $\mathrm{KOB} / \mathrm{mL}$ 'den az olması ise sütün tüketime uygun olduğunu göstermektedir (Rodrigues vd., 2017). Bununla birlikte, bilim insanlan proteolitik ve lipolitik Psendomonas veya Acinetobacter ve psikrotrofik Bacillus'un sütün bozulmasinda daha önemli bir rol oynayabileceğini, bu bakterilerin sayım ve tayininde kantitatif polimeraz zincir reaksiyonu (qPCR), akışs sitometrisi, döngü aracılı izotermal amplifikasyon (LAMP) gibi kültürden bağımsız yöntemlerin kullanılmasının daha avantajlı olabileceğini bildirmişlerdir (Trmcic vd., 2015; Agrimonti vd., 2019; Fusco vd., 2020). Beslenmede çok önemli bir yere sahip olan sütte mikroorganizma bulaşma ve gelişmesinin önlenmesi ile süt ürünlerinde de istenilen kalite ve güvenliğin sağlanması mümkün olabilecektir.

\section{ÇIKAR ÇATIŞMASI}

Yazarlar çıkar çatışması bildirmemektedir. 


\section{YAZAR KATKILARI}

Cem Sezai BAŞAR, araşturma fikri ve hipotezini oluşturulması, yürütülmesi, kaynak taranması, çalışmanın yazılmasına katkı sağlamıstır. Zeynep Dilek Heperkan, araştırma yönteminin oluşturulması, denetlenmesi, kaynak taranması, eleştirel inceleme, yazım ve dil yönüyle düzenlenmesine katk1 sağlamıştır

\section{KAYNAKLAR}

Addis, M. F., Tanca, A., Uzzau, S., Oikonomou, G., Bicalho, R. C., \& Moroni, P. (2016). The bovine milk microbiota: Insights and perspectives from-omics studies. Mol. Biosyst, 12, 2359-2372.

C6MB00217J

Agrimonti, C., Bottari, B., Sardaro, M. L. S., \& Marmiroli, N. (2019). Application of real-time PCR (qPCR) for characterizatiuon of micro- bial populations and type of milk in dairy food products. Critical Reviews in Food Science and Nutrition, 59(3), 423-442. https://doi. org/10.1080/10408398.2017.1375893

Andre, S., Vallaeys, T., Planchon, S. (2017). Spore-forming bacteria responsible for food spoilage. Res Microbiol, 168(4), 379-387. https://doi.org/10.1016/j.resmic.2016.10.003

Anonymous (2019): FAO, Overview of global dairy market developments in 2018. Retrieved from http://www.fao.org/3/ca3879en/ ca3879en.pdf

Anonymus. (2019): IFD Turkey Dairy Sector. Retrieved from https://idfwds2019.com/ en/turkey-dairy-sector.

Barbano, D.Mistanbulis., Ma, Y., Santos, M.V. (2006). Influence of raw milk quality on fluid milk shelf life J Dairy Sci 2006 Mar;89 Suppl 1:E15-9. doi:10.3168/jds.S0022-0302(06)72360-8.

Boor, K. J., Wiedmann, M., Murphy, S., Alcaine, S. (2017). A 100-Year Review: Microbiology and safety of milk handling. J Dairy Sci, 100(12), 99339951. https://doi.org/10.3168/jds.2017-12969

Caldera, L., Franzetti, L., Van Coillie, E., De Vos, P., Stragier, P., De Block, J., Heyndrickx, M. (2016). Identification, enzymatic spoilage characterization and proteolytic activity quantification of Pseudomonas spp. isolated from different foods. Food Microbiol 54 (2016) 142-153.

Caplan, Z., C. Melilli, and D. M. Barbano. (2013). Gravity separation of fat, somatic cells, and bacteria in raw and pasteurized milks. J. Dairy Sci. 96:2011-2019.

De Jonghe, V., Coorevits, A., De Block, J., Van Coillie, E., Grijspeerdt, K., Herman, L., Heyndrickx, M. (2010). Toxinogenic and spoilage potential of aerobic spore-formers isolated from raw milk. Int J Food Microbiol, 136(3), 318-325. https://doi.org/10.1016/j.ijfoodmicro.2009.11.0 07

Coorevits, A., De Jonghe, V., Vandroemme, J., Reekmans, R., Heyrman, J., Messens, W., De Vos, P., \& Heyndrickx, M. (2008). Comparative analysis of the diversity of aerobic spore-forming bacteria in raw milk from organic and conventional dairy farms. Sys. App. Microbiol., 31(2), 126-140. https://doi.org/10.1016/ j.syapm.2008.03.002

Dortey, M. D., Aboagye, G., Tuah, B. (2020). Effect of storage methods and duration of storage on the bacteriological quality of processed liquid milk post-opening. Sci Afr, 10, e00555. https://doi.org/10.1016/j.sciaf.2020.e00555

Dousset, X., Jaffrès, E., Zagorec, M. (2016). Spoilage: Bacterial Spoilage. Enc of Food and Health, 106-112. https://doi.org/10.1016/b978-0-12384947-2.00649-8

Doyle, C. J., Gleeson, D., Jordan, K., Beresford, T. P., Ross, R. P., Fitzgerald, G. F., Cotter, P. D. (2015). Anaerobic sporeformers and their significance with respect to milk and dairy products. Int J Food Microbio, 197, 77-87. https://doi.org/10.1016/j.ijfoodmicro.2014.12. 022

Fusco, V., Reşfi, D., Fanelli, F., Logrieco, AF., Cho, GS.,Kabisch, J., Böhnlein, C.,Franz, CMAP.(2020) Microbial quality and safety of milk and milk products in the 21st century. Compr Rev Food Sci Food Saf. 19(4):2013-2049. doi: 10.1111/1541-4337.12568.

Glantz, M., Rosenlöw, M., Lindmark-Månsson, H., Buhelt Johansen, L., Hartmann, J., Höjer, A., 
Paulsson, M. (2020). Impact of protease and lipase activities on quality of Swedish raw milk. Int. Dairy J, 107, 104724. https://doi.org/ 10.1016/j.idairyj.2020.104724

Golan, E., Buzby, J.C. (2015). Innovating to meet the challenge of FOOD WASTE Food Technol., 69: 21-25

Guh, A., Phan, Q., Nelson, R., Purviance, K., Milardo, E., Kinney, S., ... Cartter, M. (2010). Outbreak of Escherichia coli O157 associated with raw milk, Connecticut, 2008. Clinical Infectious Disease, 51(12), 1411-1417. https://doi.org/ $10.1086 / 657304$

Hahne J, Isele D, Berning J, Lipski A. (2019). The contribution of fast growing, psychrotrophic microorganisms on biodiversity of refrigerated raw cow's milk with high bacterial counts and their food spoilage potential. Food Microbiol. doi: 0.1016/j.fm.2018.10.019.

Holzapfel, W. H., Todorov, S. D., Cogan, T. M. (2020). History of Dairy Bacteriology. Ref Mod in Food Sci 1-10. https://doi.org/10.1016/b978-008-100596-5.23031-x http://dx.doi.org/ $10.5772 / 55937$

Jones, G., Lefèvre, S., Donguy, M. P., Nisavanh, A., Terpant, G., Fougère, E., Mariani-Kurkdjian, P. (2019). Outbreak of Shiga toxin-producing Escherichia coli (STEC) O26 paediatric haemolytic uraemic syndrome (HUS) cases associated with the consumption of soft raw cow's milk cheeses, France, March to May 2019. Euro Surveillance, 24(22), 1900305. https://doi.org/10.2807/15607917. ES.2019.24.22.1900305

Jonghe, V., Coorevits, A., Van Hoorde, K., Messens, W., Van Landschoot, A., De Vos, P., Heyndrickx, M. (2011). Influence of storage conditions on the growth of Pseudomonas species in refrigerated raw milk. Appl. Environ. Microbiol. 77, 460-470.

Júnior, JCR., Oliveira, BMD., Silva, FD.., Tamanini, R., Oliveira, BLMD., Beloti, V.(2018) The main spoilage-related psychrotrophic bacteria in refrigerated raw milk. Milk Sci. an;101(1):75-83. doi: 10.3168/jds.2017-13069.
Kirdar, SS. (2017): An overview of the Turkish dairy sector. Ind J Dairy Sci, 70, 249-255.

Koppenaal, H., Groenendiik, F., van den Berge, M., Verkade, E., Verduin, K., Zomer, A.L., Duim, B., Wagenaar, J.A., Tijsma, A.S.L., Spierenburg, M.A.H., Wierik, M.J.M. (2017). Outbreak of Campylobacter fetus infection after consumption of unpasteurized sheep's milk cheeses: how to trace the source? Ned. Tijdschr Geneeskd ;161:D1704

Lu, M., Wang, N. S. (2017). Spoilage of Milk and Dairy Products. The Microbiol Qua of Food, 151178. https://doi.org/10.1016/b978-0-08100502-6.00010-8

Machado, SG., Baglinière, F., Marchand, S., Coillie, EV., Vanetti MCD., Blok, JD., Heyndrickx, M. (2017). The Biodiversity of the Microbiota Producing Heat-Resistant Enzymes Responsible for Spoilage in Processed Bovine Milk and Dairy Products, On Mikrobiyol, Mar 1;8:302.

Martin NH, Kent DJ, Evanowski RL, Zuber Hrobuchak TJ, Wiedmann M. (2019) Bacterial spore levels in bulk tank raw milk are influenced by environmental and cow hygiene factors. J Dairy Sci. 2019 Nov; 102 (11) :9689-9701. doi: 10.3168/ jds.2019-16304. Epub 2019 Aug 22.

Martin, N. H., N. R. Carey, S. C. Murphy, M. Wiedmann, and K. J. Boor. (2012). A decade of improvement: New York State fluid milk quality. J. Dairy Sci. 95:7384-7390. http://dx.doi.org/ 10.3168/ jds.2012-5767.

Martins, ML.,Pinto, UM.,Riedel, K.,Vanetti, MCD. (2018). Quorum Sensing and Spoilage Potential of Psychrotrophic Enterobacteriaceae Isolated from Milk. Biomed Res Int. 22;2018:2723157. doi: 10.1155/2018/2723157

Miller RA., Beno SM, Kent DJ.,Carroll LM. Martin NH. Boor KJ. Kovac J. (2016). Bacillus wiedmannii sp. nov., a psychrotolerant and cytotoxic Bacillus cereus group species isolated from dairy foods and dairy environments. Int. J. Syst. Evol. Microbiol:; 66: 4744-4753

Murphy SC. Martin N. Barbano D. Wiedmann M. (2016). Influence of raw milk quality on processed 
dairy products: How do raw milk quality test results relate to product quality and yield?. J. Dairy Sci.; 99 : 10128-10149Doi:10.3168/jds.201611172

Nieminen, T., Rintaluoma, N., Andersson, M., Taimisto, A. M., Ali-Vehmas, T., Seppälä, A., Priha, O., \& Salkinoja-Salonen, M. (2007). Toxinogenic Bacillus pumilus and Bacillus licheniformis from mastitic milk. Vet. Microbiol. 124(3-4), 329-339. https://doi.org/10.1016/ j.vetmic.2007.05.015

Olajide A.M., LaPointe G. (2020). Detection of spore forming Paenibacillus macerans in raw milk. $J$ Microbiol Methods. 2020. 177:106048. doi: 10.1016/ j.mimet.2020.106048.

O'Mahony, M., Mitchell, E., Gilbert, R., Hutchinson, D., Begg, N., Rodhouse, J., Morris, J., (1990). An outbreak of foodborne botulism associated with contaminated hazelnut yoghurt. Epidemiol. Infect. 104 (03), 389-395.

Porcellato, D., Skeie, SB., Mellegård, H., Monshaugen, M., Göransson Aanrud, S., Lindstedt, BA., Aspholm, M. (2021). Characterization of Bacillus cereus sensu lato isolates from milk for consumption; phylogenetic identity, potential for spoilage and disease. J Food Microbiol, 93, 103604. https://doi.org/10.1016/ j.fm.2020.103604

Ranieri, ML., Ivy, RA., Mitchell, WR., Call, E., Masiello, SN., Wiedmann, M., Boor, KJ., (2012). Real-time PCR detection of Paenibacillus spp. in raw milk to predict shelf life performance of pasteurized fluid milk products. Appl. Environ. Microbiol. 78 (16), 5855-5863.

Ribeiro Junior JC, de Oliveira AM, Silva FG, Tamanini R, de Oliveira ALM, Beloti V. (2018). The main spoilage-related psychrotrophic bacteria in refrigerated raw milk. J Dairy Sci. 2018; 101(1):75-83. doi: 10.3168/jds.2017-13069.

Ribeiro-Júnior, JC., Tamanini, R.,Alfieri, B.,Beloti, V.(2020). Effect of milk bactofugation on the counts and diversity of thermoduric bacteria. J Sut Sci. 103(10):8782-8790. doi: 10.3168/jds.2020-18591.
Rodrigues, MX., Lima, SF., Canniatti-Brazaca, SG., Bicalho, RC. (2017). The microbiome of bulk tank milk: Characterization and associations with somatic cell count and bacterial count. J Dairy Sci, 100(4), 2536-2552. https://doi.org/10.3168/ jds.2016-11540

Ryser, ET. (2016). Pasteurization of Liquid Milk Products: Principles, Public Health Aspectsç R Mod Food Sci, 310-315. https://doi.org/10.1016/ b978-0-08-100596-5.21367-x

Sadiq, FA., Li, Y., Liu, T., Flint, S., Zhang, G., Yuan, L., Pai, Z., He, GO. (2016). The heat resistance and spoilage potential of aerobic mesophilic and thermophilic spore forming bacteria isolated from Chinese milk powders Int J Food Microbiol. 2016. 5;238:193-201. doi:10.1016/ j.ijfoodmicro.2016.09.009.

Techer, C., Jan, S., Thierry, A., Maillard, MB., Grosset, N., Galet, O., Breton, V., Gautier, M., Baron, F. (2020). Identification of the bacteria and their metabolic activities associated with the microbial spoilage of custard cream desserts. Food Microbiol; 86:103317. doi: 10.1016/j.fm.2019. 103317.

Trmcic, A., Martin, NH., Boor, KJ., Wiedmann, M. (2015). A standard bacterial isolate set for research on contemporary dairy spoilage. J Dairy Sci, 98(8), 5806-5817. https://doi.org/10.3168/ jds.2015-9490

Von Neubeck, M., Baur, C., Krewinkel, M., Stoeckel, M., Kranz, B., Stressler, T., Wenning, M. (2015). Biodiversity of refrigerated raw milk microbiota and their enzymatic spoilage potential. Int J Food Microbiol, 211, 57-65. https://doi.org/ 10.1016/j.ijfoodmicro.2015.07.001

Weiler, N., Leotta, G. A., Zuarate, M. N., Manfredi, E., Alvarez, M. E., \& Rivas, M. (2011). Foodborne outbreak associated with consumption of ultrapasteurized milk in the Republic of Paraguay. Rev Argentina de Microbiol, 43(1), 33-36. https://doi.org/10. 1590/s032575412011000100007

Wyder, MTF., Roth, EA., Jakob, E. (2019). Cheese yeasts, Wiley Yeast Maya, 36(3):129-141. doi: $10.1002 /$ yea.3368. 
Young, W., Hine, B. C., Wallace, O. A. M., Callaghan, M., Bibiloni, R. (2015). Transfer of intestinal bacterial components to mammary secretions in the cow. PeerJ, 3, Article e888. https://doi.org/10.7717/peerj.888.

Yuan L, Sadiq FA, Burmølle M, Wang NI, He G. (2019). Insights into Psychrotrophic Bacteria in Raw Milk: A Review. J Food Prot. 82(7):1148-1159. doi: 10.4315/0362-028X.JFP-19-032. PMID: 31225978 .

Yuan, L., Sadık, F., Liu , TJ., Li, Y., Gu, JS.,Yang, HY., Guo-Qing O. (2018). Spoilage potential of psychrotrophic bacteria isolated from raw milk and the thermo-stability of their enzymes Zhejiang Univ Sci B. 19(8):630-642. doi: 10.1631/jzus. B1700352.

Zhang, C., Bijl, E., Svensson, B., Hettinga, K. (2019). The Extracellular Protease AprX from Pseudomonas and its Spoilage Potential for UHT Milk: A Review. Compr Rev Food Sci Food Saf. 18(4):834-852. doi: 10.1111/1541-4337.12452. 